\title{
Dietary protein regime effect on the goblet cells, intraepithelial leukocyte count, and mast cell distribution in gastrointestinal tract of broilers
}

Amira. A. Naidany; Osman, A .K.; Eidaroos, H., and Abdelalim, E. M. Department of cytology and histology, Faculty of veterinary medicine, Suez canal university, Ismailia, Egypt.

\begin{abstract}
Day one, Cobb chicks were employed to investigate the effects of different levels of dietary crude protein (CP) on the distribution of goblet cells (GCs), mast cells (MCs), and intraepithelial leukocytes (IELs) in broilers gastrointestinal tract. Chicks were randomly allotted to three treatments, containing CP 20\%, $22 \%$, and $24 \%$. At 42 days, three chicks of each treatment were slaughtered and the samples from the gastrointestinal tract were taken, processed, and stained with H\&E and special stains. Results showed that the GC count increased in the low protein (LP) diet and decreased in high protein (HP) diet, while the IELs increased in the HP diet and decreased in the LP diet. Mast cell distribution was much more obvious in the LP and NP diets comparatively with the HP diet.
\end{abstract}

\section{Introduction}

Gut-associated lymphoid tissues (GALT) of the intestine are part of the common mucosal immune system of poultry, considering birds lack classic well defined lymph nodes (Megan and Catherine, 2013). Many functional properties have been ascribed to intestinal mucin, such as lubricating intestinal surfaces, trapping, and neutralizing bacteria, detoxifying heavy metal binding, acting as a diffusion barrier for nutrients and macromolecules, and protecting the underlying epithelial cells, protection to the mucosa from dehydration and mechanical damage (Khan, 2008). Mast cells together with humoral and cellular defense cells have important role within that system (Caldwell et al, 2001). Moreover, the lining epithelium is protected by mucosal secretions and by the penetrating IELs. The IELs of the chicken are a population of lymphocytes including Natural killer (Gobel et al, 2001), as well as $\mathrm{Bu}-1$ bearing cells (not classical B cells) (Vervelde and Jeurissen, 1993).

\section{Materials and Method}

I- Birds housing and feeding system

This study was conducted on 90, one day-old Cobb broiler chicks, which have been brought from a hatching chick's house (Abu Atwa, Ismailia). The experimental diets were formulated to be ISO-caloric, 
The broilers were divided into three groups according to the protein level in the diet (Table 1). Birds were given feed and water full day with a continuous artificial lighting till the end of the experiment. The ambient temperature was $30{ }^{\circ} \mathrm{C}$ in the first three weeks than decreased to $24^{\circ} \mathrm{C}$.

II- Collection and preparation of the samples

At the end of the experimental period, three birds per group were randomly selected, slaughtered, and dissected. Tissue samples were taken from proventriculus, small intestine, and large intestine. Small slices about $5.0 \mathrm{~mm}$ cubes from the aforementioned organs were excised and fixed in $4 \%$ paraformaldehyde (PH 7.4), trimmed, and dehydrated manually cleared in xylene, embedded in paraffin, sectioned stained by Hematoxylin and eosin (H\&E) Alcian Blue, Periodic acid schiff reagent and Toluidine blue and mounted in a DPX.

III- Goblet cells (GCs) and intraepithelial leukocytes (ILEs)

The IELs and the GCs along intact villi were counted under a bioccular microscope using high magnification (40x) and each count was repeated five times for each section ( $G u$ and li, 2004).

Table (1): Ingredient composition of the different levels of protein diets us

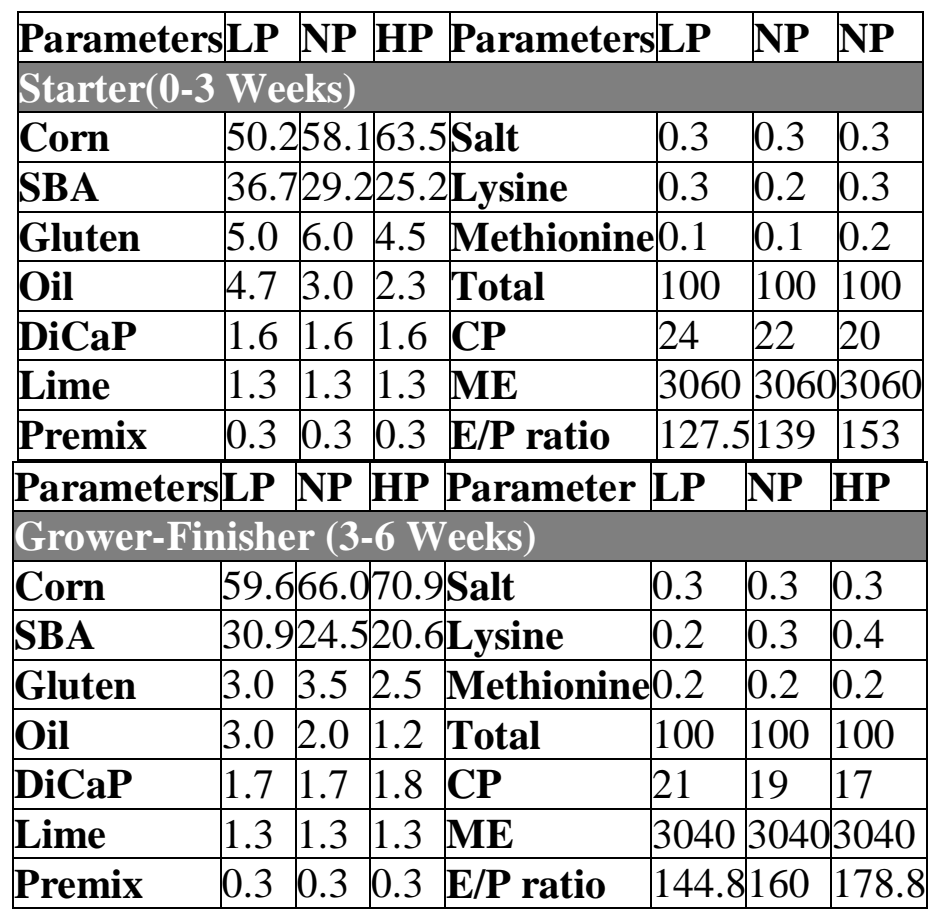




\section{Results}

A strong $\mathrm{PAS}$ and $\mathrm{AB}$ positive reaction was observed in the brush border of the epithelial lining and the GCs in the intestinal villi and crypts in all groups in duodenum (Fig. 1), jejunum (Fig 2), ileum (Fig 3 ), cecum (Fig 4) and colo-rectum (Fig 5). Dietary CP had a highly significant effect on the GCs population in the duodenum ( $P$ 0.001), which showed marked decrease as the dietary CP increased (Table 2). GCs count in the epithelium and crypts of the jejunum were significantly (P 0.001) different among the CP treatments where in the NP group goblet cell count was lesser than other groups (Table 2).

The total GCs count in the villi and crypts in the ileum of all groups were nearly the same, whereas the GCs count showed a slight increase in LP and NP groups $(P \sim 0.15)$ (Table 2). GCs count had significant differences among the groups (P 0.001). GCs count in cecum was numerous in the LP and HP groups, while they were less numerous in NP group (Table 2). GC count in recto-colon was lower than that of cecum and it was of no significant variation between groups (P 0.090) (Table 2).

Mast cells (MCs) stained by toluidine blue were much more obvious in LP groups than those of NP group and decreased in number in the HP group.

MCs were observed among the connective tissue elements of the lamina propria and submucosa of the examined GIT organs. They were markedly obvious in perivascular, periglandular, and perineural localities.

Toluidine blue stained sections revealed that the MCs had various sizes and shapes. They were flat, oval or spindle shaped. MCs were determined at most in proventriculus in lamina propria basically (Fig. 6). In small intestine, MCs in the jejunum were concentrated in the upper part of the jejunal villi (Fig 6) and they were numerous in the jejunum than in the duodenum and ileum (Fig.6). They were observed more frequently in the mucosal epithelial lining and lamina propria than around crypts in LP and NP groups then become less in HP group (Fig.6). In large intestine, distribution of MCs was less abundant in cecum than in colonrectum, where they were numerous and located around crypts (Fig. 6).

The intraepithelial leukocytes (IELs) were observed mostly between columnar cells of the epithelial lining. Globule leukocytes (GLs) were scattered mainly in crypts while GLs were twice in size than those of IELs (Fig. 7). IELs have small spherical bodies with clear perinuclear halo, while GLs were larger with acidophilic intracytoplasmic granules and darkly basophilic nucleus. Sections of GLs stained by toluidine blue showed their metachromasia where they stained violet red (Fig. 7). 
In the duodenum, the distribution of IELs was lesser in the LP than in the other groups while no significant variation was seen between the NP and HP groups (Table 2). In the jejunum, the response of the IELs to the dietary $\mathrm{CP}$ level was also significant (P 0.001), since IEL count was lesser in the NP group (Table 2). In the ileum, although the count of IELs was the highest in the HP group, it showed no significant
(P 0.10) difference among the groups (Table 2).

In the cecum, the distribution of IELs was lesser than those of small intestine with a significant difference among the groups (P 0.011). They showed more scattered pattern in the HP group in comparison to those in in LP and NP groups (Table 2). In the rectocolon, the IELs were in general lesser than those of cecum and they were of no significant $(\mathrm{P} \sim 0.138)$ variation between groups.

Table (2): The effect of different levels of CP on Goblet cells and Intraepithelial leucocytes

\begin{tabular}{|l|l|l|l|l|}
\hline Parameters & LP & NP & HP & P-Value \\
\hline Goblet Cells Count \\
\hline Duodenum & $\begin{array}{l}2591.67^{\mathrm{a}} \\
\pm 4.9\end{array}$ & $\begin{array}{l}2355.34^{\mathrm{a}} \\
\pm 17.8\end{array}$ & $\begin{array}{l}1710.12^{\mathrm{b}} \\
\pm 12.5\end{array}$ & 0.001 \\
\hline Jejunum & $\begin{array}{l}4011.68^{\mathrm{a}} \\
\pm 17.41\end{array}$ & $\begin{array}{l}013.34^{\mathrm{a}} \\
\pm 7.23\end{array}$ & $\begin{array}{l}3685^{\mathrm{b}} \\
\pm 40.72\end{array}$ & 0.001 \\
\hline Ileum & $\begin{array}{l}3506.63^{\mathrm{a}} \\
\pm 24.5\end{array}$ & $\begin{array}{l}3236.53^{\mathrm{a}} \\
\pm 32.1\end{array}$ & $\begin{array}{l}3027^{\mathrm{a}} \\
\pm 34.2\end{array}$ & 0.15 \\
\hline Cecum & $\begin{array}{l}322^{\mathrm{a}} \\
\pm 5.7\end{array}$ & $\begin{array}{l}215.47^{\mathrm{c}} \\
\pm 7.6\end{array}$ & $\begin{array}{l}280^{\mathrm{b}} \\
\pm 4.4\end{array}$ & 0.001 \\
\hline Colo-rectum & $\begin{array}{l}187.04^{\mathrm{b}} \\
\pm 4.7\end{array}$ & $\begin{array}{l}195.64^{\mathrm{a}} \\
\pm 2.8\end{array}$ & $\begin{array}{l}164.52^{\mathrm{b}} \\
\pm 1.9\end{array}$ & 0.090 \\
\hline
\end{tabular}

\begin{tabular}{|l|l|l|l|l|}
\hline Parameters & \multicolumn{1}{|c|}{ LP } & \multicolumn{1}{|c|}{ NP } & \multicolumn{1}{|c|}{ HP } & P-Value \\
\hline Intraepithelial leucocytes (IELs) Count \\
\hline Duodenum & $\begin{array}{l}301.83^{\mathrm{b}} \\
\pm 4.4\end{array}$ & $\begin{array}{l}401.71^{\mathrm{a}} \\
\pm 8.8\end{array}$ & $\begin{array}{l}433.38^{\mathrm{a}} \\
\pm 4.7\end{array}$ & 0.001 \\
\hline Jejunum & $\begin{array}{l}148.03^{\mathrm{b}} \\
\pm 4.1\end{array}$ & $\begin{array}{l}128.23^{\mathrm{c}} \\
\pm 3.3\end{array}$ & $\begin{array}{l}170.11^{\mathrm{a}} \\
\pm 7.6\end{array}$ & 0.005 \\
\hline Ileum & $\begin{array}{l}235^{\mathrm{b}} \\
\pm 2.8\end{array}$ & $\begin{array}{l}245^{\mathrm{b}} \\
\pm 10.9\end{array}$ & $\begin{array}{l}301.62^{\mathrm{a}} \\
\pm 7.6\end{array}$ & 0.10 \\
\hline Cecum & $\begin{array}{l}30^{\mathrm{b}} \\
\pm 2.8\end{array}$ & $\begin{array}{l}32^{\mathrm{b}} \\
\pm 2.8\end{array}$ & $\begin{array}{l}45^{\mathrm{a}} \\
\pm 1.6\end{array}$ & 0.011 \\
\hline Colo-rectum & $\begin{array}{l}15.19^{\mathrm{a}} \\
\pm 2.8\end{array}$ & $\begin{array}{l}18.52^{\mathrm{a}} \\
\pm 3.2\end{array}$ & $\begin{array}{l}20.92^{\mathrm{a}} \\
\pm 2.1\end{array}$ & 0.138 \\
\hline
\end{tabular}




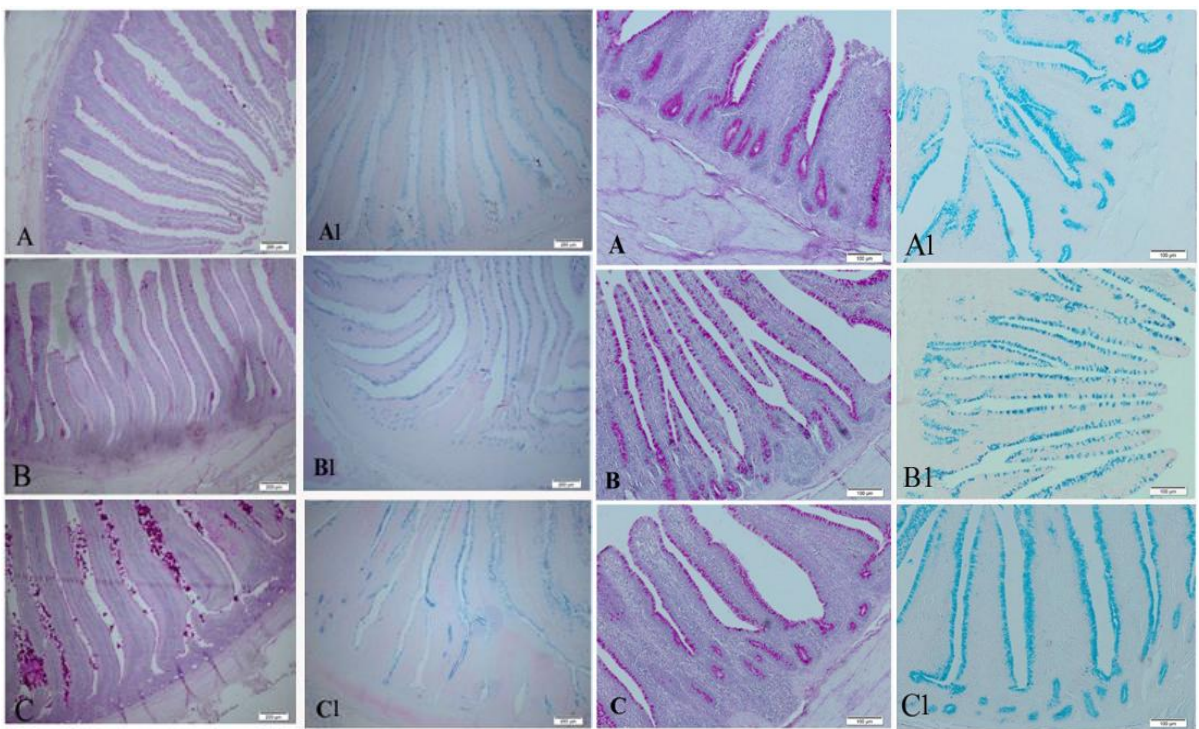

Fig. (1): A section of duodenum showing a strong PAS-positive reaction staining the goblet cells of the duodenal villi and crypts in LP group (A), NP group $(B)$ and HP group $(C)$. A strong Alcian Blue (AB)-positive reaction staining the goblet cells of the duodenum in the LP group (A1), NP group (B1) and HP group (C1).

Fig. (2): A section of jejunum showing a strong PAS-positive reaction staining the goblet cells of the jejunal villi and crypts in LP group (A), NP group $(B)$ and HP group (C). A strong Alcian Blue (AB)-positive reaction staining the goblet cells of the jejunum in the LP group (A1), NP group (B1) and HP group $(\mathrm{C} 1)$.

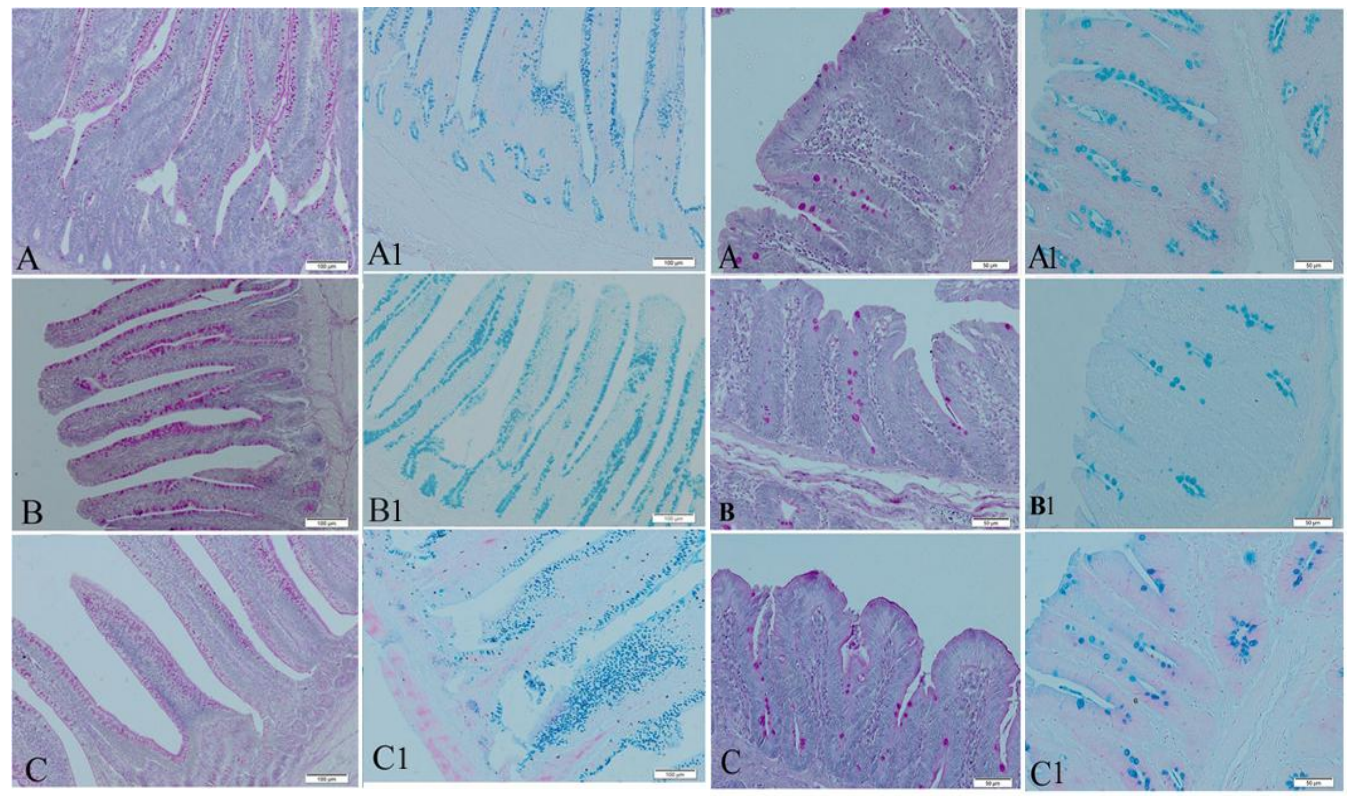


Fig. (3): A section of ileum showing a strong PAS-positive reaction staining the goblet cells of the ileal villi and crypts in LP group (A), NP group(B) and HP group $(\mathrm{C})$. A strong Alcian Blue $(\mathrm{AB})$-positive reaction staining the goblet cells of the ileum in the LP group (A1), NP group (B1) and HP $\operatorname{group}(\mathrm{C} 1)$.

Fig. (4): A section of cecum showing a strong PAS-positive reaction staining the goblet cells of the cecal villi and crypts in LP group (A), NP group(B) and HP group $(\mathrm{C})$. A strong Alcian Blue $(\mathrm{AB})$-positive reaction staining the goblet cells of the cecum in the LP group (A1), NP group (B1) and HP $\operatorname{group}(\mathrm{C} 1)$.

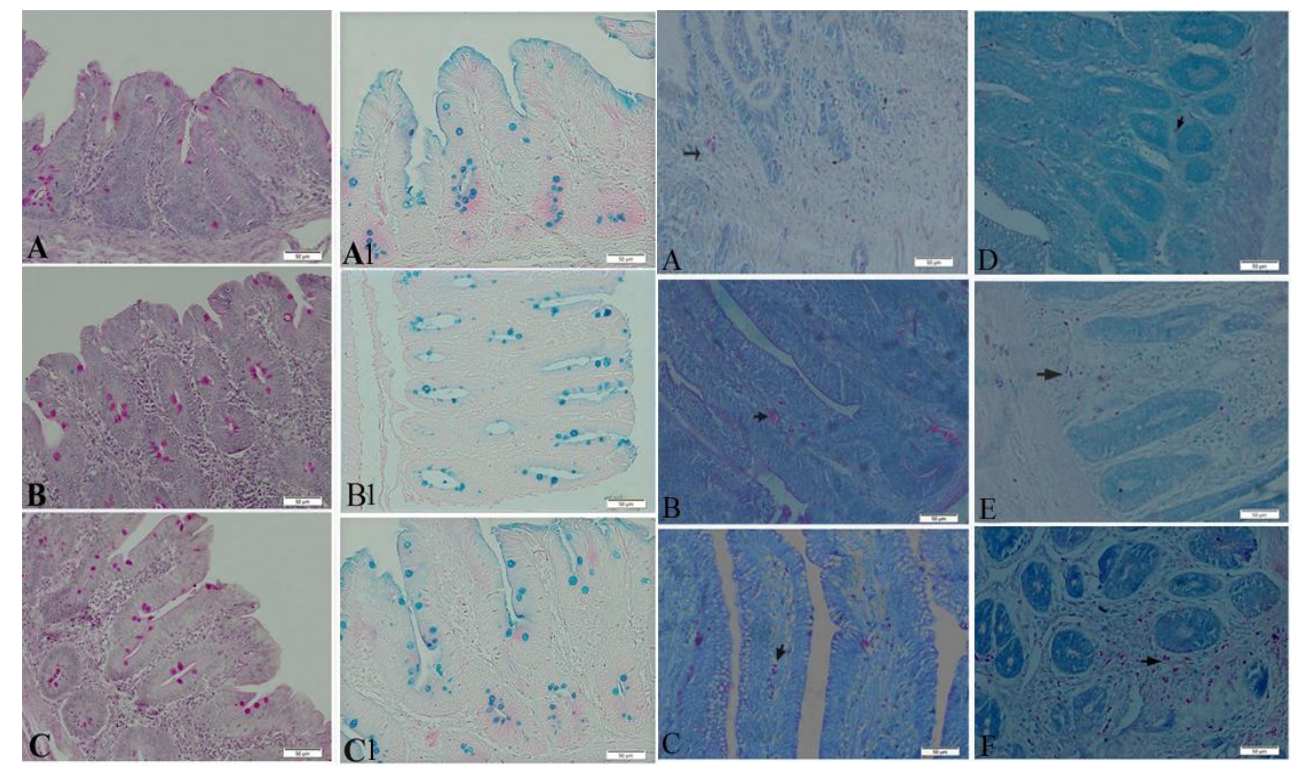

Fig. (5): A section of colo-rectum showing a strong PAS-positive reaction staining the goblet cells of the colo-rectal villi and crypts in LP group (A), $\mathrm{NP}$ group(B) and HP group (C). A strong Alcian Blue (AB)-positive reaction staining the goblet cells of the colo-rectum in the LP group (A1), NP group (B1) and HP group(C1).

Fig. (6): A section showing mast cells (arrow) distribution in the proventriculus (A)and the small intestine, in duodenum (B), in jejunum (C) and in ileum(D), In cecum (E) and in the colo-rectum (F). 

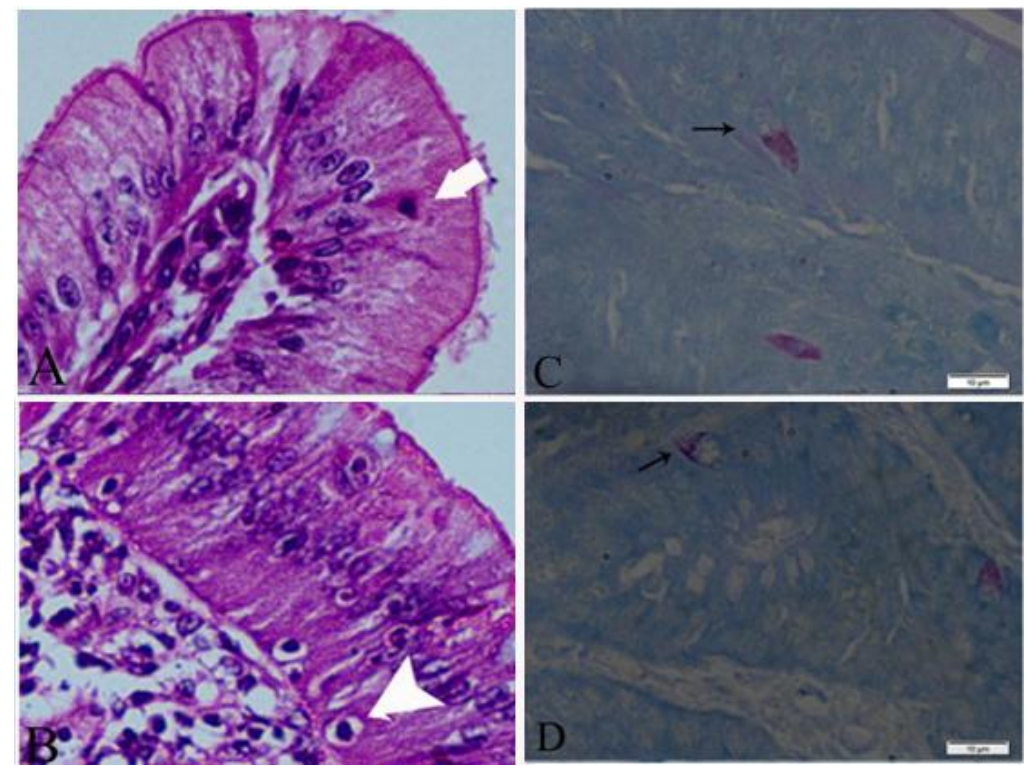

Fig (7) A section showing Globule Leucocytes (GLs) (arrow) (A) and the IELs (arrow head) (B) in the intestinal villi stained by H\&E. GLs in the lining epithelium of the intestinal villi. (B) and crypt (D) stained by Toluidine blue.

\section{Discussion}

In this study, a positive PAS and $\mathrm{AB}$ reactivity of the goblet cells of the small intestine in all groups, suggesting that the crypts of Leiberkühn had an acid and neutral muco-polysaccharide secretions. These findings are in agreement with (El-Sayyad, 1995).

The total goblet cells count showed a marked increase in broilers fed the LP diet followed by those fed NP diet and relatively decreased in broilers fed the HP diet. In duodenum and jejunum the highest count was observed in the LP group, while in ileum the GCs count were nearly the same. Our result are in accordance with Langhout et al (1999) who reported a significantly increased number of GCs per unit area of intestinal mucosa with decreased villi length, suggesting that the higher density of GCs may result in an increase in the secretion of mucin. Moreover, Kritchevsky and Bonfield (1995) added that shorter villi relative to crypts depths have fewer absorptive cells but more secretary cells. It has been reported that a decrease in digesta viscosity as results of decreased the CP level increases the amount of mucins (Sharma et al, 1997).

By increasing the crude protein level (HP) the goblet cell number was reduced. This finding matches the observations of Wu et al (2004) who showed that by elevating the CP level the GCs population decreases, because when dietary $\mathrm{CP}$ increases, lower proportion of 
endogenous amino acids is lost in digesta and excreta. This finding assuring that LP diet improved the immunity and gut health rather than the high protein diet.

In harmony with Montagne et al (2004), the GCs count was the highest in jejunum rather than duodenum and ileum particularly in the LP group, considered that the jejunum was the longest part of the small intestine, responsible for most of the nutrient absorption, and the alterations observed in the dynamics of mucin secretion within the gut should probably contribute for a higher absorption of the small amount of amino acids provided in the diet which will be used in the synthesis of mucin glycoprotein in the goblet cells.

Montagne et al (2004) added that a greater quantity of mucins is produced at the surface of the jejunum helping in slowing the rate of nutrient absorption by decreasing the viscosity of food and time need to mix the digests with the bile salt and digestive enzymes. Our results showed no significant differences in total goblet cells count in ileum in all groups. The same findings have been reported by Montagne et al (2000) who suggested that GCs and mucin protein represent a significant component of endogenous secretions to food pass undigested to the terminal ileum.

Our results showed that the cecal and recto-colonal villi and cryptal epitheliocytes exhibited higher acid mucin content whereas neutral mucin was much lower. These findings are in line with Sharma et al (1997) who mentioned that alternations in the type of mucin produced are due to changes in diets composition. It has been suggested that acidic mucins protect against bacterial translocation because sulfomucins in particular appear to be less degradable by bacterial glycosidases and host proteases (DePlancke and Gaskins, 2001). In contrast, the total GC counts in the recto-colon showed lesser populations than cecum and revealed slight variations among the three groups where the highest was in NP group. Our results are constituent with the findings of Hedemann et al (2005) who reported that the mucin staining area in the cecum and recto-colon was not affected in pigs fed coarse grounded pellets.

\section{Mast cells (MCs)}

Generally, the results showed that the distribution of the MCs in the jejunum was concentrated in the upper part of the villus in birds fed on coarsely ground diet. The population of MCs was significantly lower in the duodenum, ileum, and cecum compared with the proventriculus, jejunum and colo-rectum. Our results are in harmony with $\mathbf{L i u}$ et al (2006) showed that reducing particle size enhances the number of mast cells and increases the histamine synthesis, through increasing stem cell factor 
concentration and expression in the small intestine in broiler chickens.

In accordance with Leren (2003) similar distribution of MCs were observed in lamina propria, submucosa, around glands, near blood vessels and between muscle groups in tunica muscularis all over the gastrointestinal tract of all groups. In our study, mast cells were much more obvious in the LP group than those of NP and decreased in number in the HP group. Marshall (2004) observed that an increase in mast cell numbers might result in an increase in the production and release of active mediators that regulate the movement of intestinal smooth muscle.

$\mathrm{MCs}$ in proventriculus were distributed evenly in the lamina propria, and between oxynticopeptic cells especially in the LP group. Our results are in line with Yoruk (2004) who reported that MCs were determined in proventriculus, which recorded the highest localization of mast cell. MCs in jejunum were seen more frequently in the mucosa and lamina propria more than around crypts. These results agree with a previous report showed the same distribution in chicken jejunum (Darmawi et al, 2013). MCs were present mainly in the LP and NP groups then become less in number in HP group.

MCs showed a marked decrease in the duodenum and ileum compared to jejunum. MC population was observed in the proximal part of the jejunal villus. Our results are in harmony with Liu et al (2006) who showed that mast cells in the jejunum were concentrated in the upper part of the villus in birds fed the coarsely ground mash diet, The number of MCs was significantly lower in the duodenum, ileum and higher in jejunum of birds fed coarsely ground diets. Furthermore the mast cell distribution in rectocolon where Clostridium perfringens are expected to increase were more than in cecum, our results are not in accordance with Yoruk (2004) who reported a marked decrease in mast cells in cloacae-rectum.

The distribution of IELs in the small intestine, cecum, and rectocolon showed variations in the three groups of the experiment. Our results are in accordance with Turner (2009) who stated that the IELs were dispersed among the enterocytes that line intestinal villous, playing a role in gut immune function. $\boldsymbol{W u}$ (2009) reported that such function needs at least some exogenous glutamine. Our results showed an increase in the number of IELs in the duodenum and jejunum, and a decrease in number in the middle part of the cecum and in the colon. These findings come along with the findings of (Vervelde and Jeurissen, 1993), moreover, a marked increase in IELs count in broilers fed the HP diet especially in the upper small intestine, with 
nearly even distribution in the ileum. In large intestine, cecum continued as the same manner as ileum. While in recto-colon the distribution was lesser than in cecum but was evenly localized. In pigs $\boldsymbol{G u}$ and $\boldsymbol{L i}$ (2004) reported a decrease in IELs count during feeding higher levels of dietary protein.

GLs were stained violet red with characteristic acidophilic granules by toluidine blue and were observed in the epithelial lining of both villus and crypts of the duodenum. Our findings are in line with Masum et al (2012) who mentioned that the mucosal epithelia of chickens contained different types of migrating immunocompetent cells, such as GLs.

\section{References}

Caldwell, D. J.; Harari, Y.; Hargis, B. M. and Castro, G. A. (2001): Intestinal anaphylaxis in chickens: Epithelial ion secretion asa determinant and potential component of functional immunity. Dev. Comp. Immunol. 25: 169-176.

Darmawi, U. B.; Hambala, M.; Tiuriab, R.; Frengkia, B. and Priosoeryantob, P. (2013): Mucosal mast cells response in the jejunum of Ascaridia galli-Infected laying hens. Media Peternakan, pp. 113-119.

DePlancke, B. and Gaskins, H.R. (2001): Microbial modulation of innate defense: Goblet cells and the intestinal mucus layer. Am. J. Clin. Nutr.,73:S1131-S1141.
El-Sayyad, H.I.H.

(1995):

Structural analysis of the alimentary canal of hatching youngs of the owl Tyto alba alba. Journal of the Egyptian German Society Zoology., 16(C): 185-202.

Gobel, T.W.; Kaspers, B. and Stangassinger, M. (2001): NK and $\mathrm{T}$ cells constitute two major, functionally distinct intestinal epithelial lymphocyte subsets in the chicken. Int Immunol, 13: 757-62.

Gu, X. and Li D. (2004): Effect of dietary crude protein level in villous morphology, immune status and histochemistry parameters of digestive tract in weaning piglets. Anim. Feed Sci. Technol. 114, 113126.

Hedemann, M.S.; Mikkelsen, L.L.; Naughton, P.J. and Jensen, B.B. (2005): Effect of feed particle size and feed processing on morphological characteristics in the small and large intestine of pigs and on adhesion of Salmonella enterica serovar Typhimurium DT12 in the ileum in vitro.J Anim Sci., 83(7):1554-62.

Khan, W.I. (2008): Physiological changes in the gastrointestinal tract and host protective immunity: learning from the mouse-Trichinella spiralis model. Parasitology, 135, 671-682.

Kritchevsky, D. and Bonfield, C. (1995): Dietary Fiber in Health and Disease. 1st Edn., Plenum Press, New York, ISBN-10: 325.

Langhout, D.J.; Schutte, J.B.; Vanleeuwen, P.; Wiebeng, J. and Tamminga, B. (1999): Effect of 
dietary high-and low-methylated citrus pectin on the activity of the ileal microflora and morphology of the small intestinal wall of broiler chicks. Br. Poult. Sci., 40: 340-347.

Leren, X.; Deyuan, $O$. and Denghui, G. (2003): Characterization of Mast Cells in Chicken. Journal of Animal and Veterinary Advances Volume: 2(1): 38-43.

Liu, Y.H.; Piao, X.S.; Ou, D.Y.; Cao, Y.H.; Huang, D.S. and Li, D.F. (2006): Effects of particle size and physical form of diets on mast cell numbers, histamine, and stem cell factor concentration in the small intestine of broiler chickens. Poult Sci., 85(12):2149-55.

Marshall, J. S. (2004): Mast-cell responses to pathogens. Nat. Rev. 4:787-799.

Masum, M. A,; Khan, M. Z. I.; Siddiqi , M. N. H.; Nasrin, M. and Sultana, N.(2012): Frequency and distribution of immunoglobulin containing plasma cells in ileum representing gut-associatedlymphatic tissues in the BCRDVvaccinated broiler. Bangl. J. Vet. Med.,10 (1\&2): 15-20.

Megan, R.R. and Catherine, J.F. (2013): The immune modifying effects of amino acids on gutassociated lymphoid tissue. J Field J Anim Sci Biotechnol., (1): 27.

Montagne, L.; Piel, C. and Lallès, J. P. (2004): Effect of diet on mucin kinetics and composition: nutrition and health implications. Nutr. Rev., 62(3):105-14.
Montagne, L.; Toullec, R.; Formal, M. and Lalles, J. P. (2000): Influence of dietary protein level and origin on the flow of mucin along the small intestine of the preruminant calf. J. Dairy Sci. 83:2820-2828.

Sharma, R.; Fernandez, F.; Hinton, M. and Schumacher, U. (1997): The influence of diet on the mucin carbohydrates in the chick intestinal tract. Cell Mol Life Sci.,53(11-12):935-42.

Turner, J.R. (2009): Intestinal mucosal barrier function in health and disease. Nat Rev Immunol, 9:799-809.

Vervelde, L. and Jeurissen, S.H. (1993): Postnatal development of intra-epithelial leukocytes in the chicken digestive tract: phenotypical characterization in situ. Cell Tiss Res., 274(2): 295301.

Wu, G. (2009): Amino acids: metabolism, functions, and nutrition. Amino Acids, 37:1-17.

Wu, Y. B.; Ravindran, V.; Thomas, D. G.; Birtles, M. J.; Hendriks, W. H. (2004): Influence of Phytase and Xylanase, Individually or in Combination, on Performance, Apparent Metabolisable Energy, Digestive Tract Measurements and Gut Morphology in Broilers Fed Wheat based Diets Containing Adequate Levels of Phosphorous. Br. Poultry Sci., 45: 76-84.

Yoruk, T.K.M. (2004): A Morphological and Histometrical Study on Distribution and 
Heterogeneity of Mast Cells of Tract. YYU Vet Fak Derg, 15 (1Chicken's and Quail's Digestive 2):115-121.

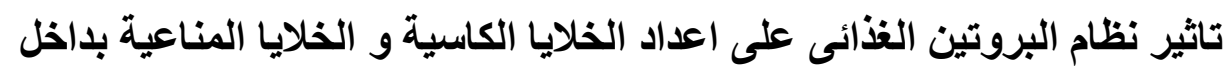

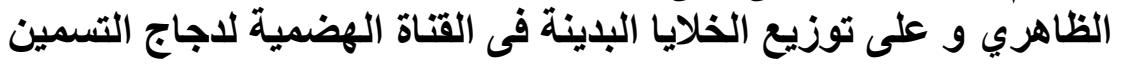

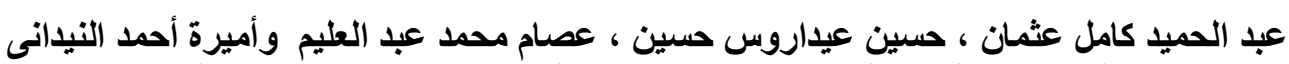

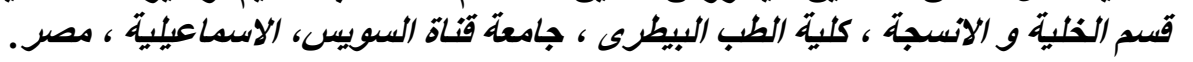

$$
\text { الملخص العربى }
$$

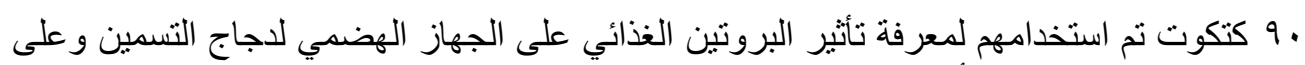

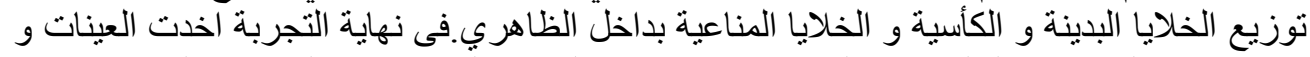

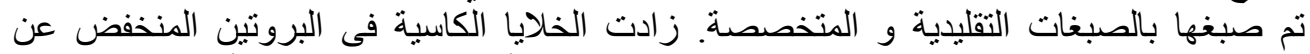

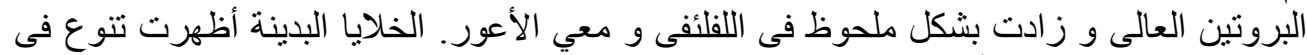

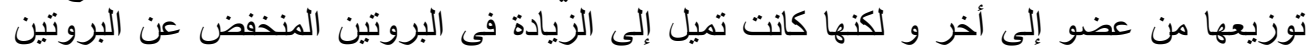

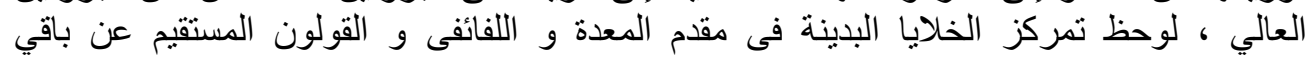

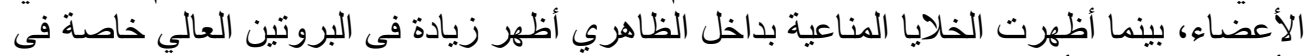
الأجز اء الثثلاثة للأمعاء الدقبقة. 